\title{
Synaptic Plasticity in the Human Dentate Gyrus
}

\author{
Heinz Beck, Ivan V. Goussakov, Ailing Lie, Christoph Helmstaedter, and Christian E. Elger \\ Department of Epileptology, University of Bonn Medical Center, D-53105 Bonn, Germany
}

Activity-dependent plasticity is a fundamental feature of most CNS synapses and is thought to be a synaptic correlate of memory in rodents. In humans, NMDA receptors have been linked to verbal memory processes, but it is unclear whether NMDA receptor-dependent synaptic plasticity can be recruited for information storage in the human CNS.

Here we have for the first time analyzed different forms of synaptic plasticity in human hippocampus. In human subjects who show a morphologically intact hippocampus that is not the primary seizure focus, NMDA receptor-dependent long-term potentiation (LTP) and forskolin-induced long-lasting potentiation are readily induced at the perforant path-dentate gyrus synapse. In this group, long-term potentiation could be partially depotentiated by low-frequency stimulation.

Because patients with a hippocampal seizure focus showed a marked reduction in verbal memory performance in previous studies, we asked whether synaptic plasticity is similarly affected by the presence of a hippocampal primary seizure focus. We found that the amount of potentiation induced by high-frequency stimulation or perfusion of forskolin is dramatically reduced in this patient group. In addition, low-frequency stimulation is not effective in inducing synaptic depression.

In summary, we show that activity-dependent synaptic plasticity with properties similar to the rodent is available for information storage in the human hippocampus. Because both verbal memory processes and synaptic plasticity are impaired by a hippocampal seizure focus, we suggest that impaired synaptic plasticity may contribute to deficient declarative memory in human temporal lobe epilepsy.

Key words: hippocampal synaptic plasticity; N-methyl-D-aspartate; human; dentate gyrus; temporal lobe epilepsy; declarative memory
The ability to modify the strength of synaptic transmission in an activity-dependent manner is a fundamental feature of most excitatory CNS synapses investigated in rodents. The fact that the history of previous activation can determine the efficacy of synaptic transmission for hours or even days has made synaptic plasticity a particularly attractive model for information storage in the CNS. Long-term potentiation (LTP) is a striking form of synaptic plasticity induced by high-frequency stimulation that is thought to be a potential synaptic analog of long-lasting memory (Bliss and Lomo, 1973; Bliss and Collingridge, 1993; Malenka and Nicoll, 1993). Therefore, most experimental studies of LTP have focused on the hippocampus, a structure central for learning and memory (Squire, 1992). The best studied form of LTP is dependent on the activation of NMDA receptors and subsequent increases in the postsynaptic $\mathrm{Ca}^{2+}$ concentration and occurs in different hippocampal pathways, e.g., the perforant path-dentate granule cell synapse and the Schaffer collateral-CA1 synapse.

A great number of studies have attempted to determine whether NMDAR-dependent long-term potentiation indeed underlies memory processes in rodents. In initial studies, block of NMDA receptors in vivo caused spatial learning deficits and prevented LTP induction (Morris et al., 1986; Morris, 1989; Davis et al., 1992; Bannerman et al., 1995; Saucier and Cain, 1995). Similar results were obtained in transgenic mice lacking genes important in the induction or expression of hippocampal synaptic plasticity (Grant et al., 1992; Silva et al., 1992a,b). These results are consistent with the notion that hippocampal synaptic plasticity underlies spatial memory in rodents, but the lack of regional or temporal specificity of the pharmacological and genetic manipulations has also permitted other explanations. More recently, selective elimination of

Received Feb. 2, 2000; revised June 22, 2000; accepted June 30, 2000.

This research was supported by Deutsche Forschungsgemeinschaft (DFG) Grant EL 122 7-1, the German-Israel Program of the Bundesministerium für Bildung und Forschung, the Sonderforschungsbereich 400 of the DFG, and the graduate program of the University of Bonn, "Pathogenesis of CNS Diseases." We thank Prof. Schramm, Prof. Zentner, and Dr. van Roost for providing neurosurgical specimens.

Correspondence should be addressed to Dr. Heinz Beck, Department of Epileptology, University of Bonn Medical Center, Sigmund-Freud Strasse 25, D-53105 Bonn, Germany. E-mail: heinz@mailer.meb.uni-bonn.de.

Copyright (C) 2000 Society for Neuroscience $0270-6474 / 00 / 207080-07 \$ 15.00 / 0$ genes in specific hippocampal cell types or during specific periods has been used to address this issue more specifically (Mayford et al., 1996; McHugh et al., 1996; Tsien et al., 1996; Rotenberg et al., 1996). Thus, despite the obvious shortcomings, parallel investigations of LTP and memory performance have remained a major tool for probing the relation of synaptic plasticity and memory in rodents. In the human, available evidence indicates that hippocampal NMDA receptors are necessary for mediating repetition/recognition effects of limbic event-related potentials (anterior mesial temporal lobe-N400s) to continuous word recognition paradigms as well as for intact verbal memory performance in neuropsychological investigations (Grunwald et al., 1999). Both verbal memory performance as well as repetition effects of anterior mesial temporal lobe-N400s are significantly reduced by the presence of a hippocampal seizure focus (Helmstaedter et al., 1997).

This raises the question of (1) whether NMDA receptordependent synaptic plasticity is a feature of adult human hippocampal synapses and thus a possible basic mechanism of human declarative memory and (2) whether LTP impairment in neurological disease is paralleled by deficient declarative memory performance. To answer these critical questions, we have exploited the unique opportunity to analyze properties of LTP in surgically resected human hippocampal specimens from temporal lobe epilepsy (TLE) patients and a nonepileptic control hippocampus. We demonstrate that patients with an extrahippocampal primary seizure focus show classical NMDA receptor-dependent LTP as well as long-lasting potentiation (LLP) induced by an increase in the intracellular cAMP concentration. In contrast, patients with a hippocampal primary seizure focus and selective hippocampal damage show severely reduced LLP and LTP. We suggest that impaired synaptic plasticity in this patient group may account for deficient declarative memory observed in these patients.

\section{MATERIALS AND METHODS}

Human subjects. Surgical specimens from 29 patients with TLE that were not sufficiently responsive to pharmacotherapy were obtained for electrophysiological analysis (average age at surgery $31.0 \pm 12.2$ years). The mean duration of TLE in the adult patients was $15.2 \pm 7.5$ years (mean \pm SEM), and the mean age at the onset of seizures was $15.8 \pm 8.7$ years. Patients were divided into two groups. One group had a histopathological diagnosis of solitary Ammon's horn sclerosis (AHS) with severe neuronal loss in the 


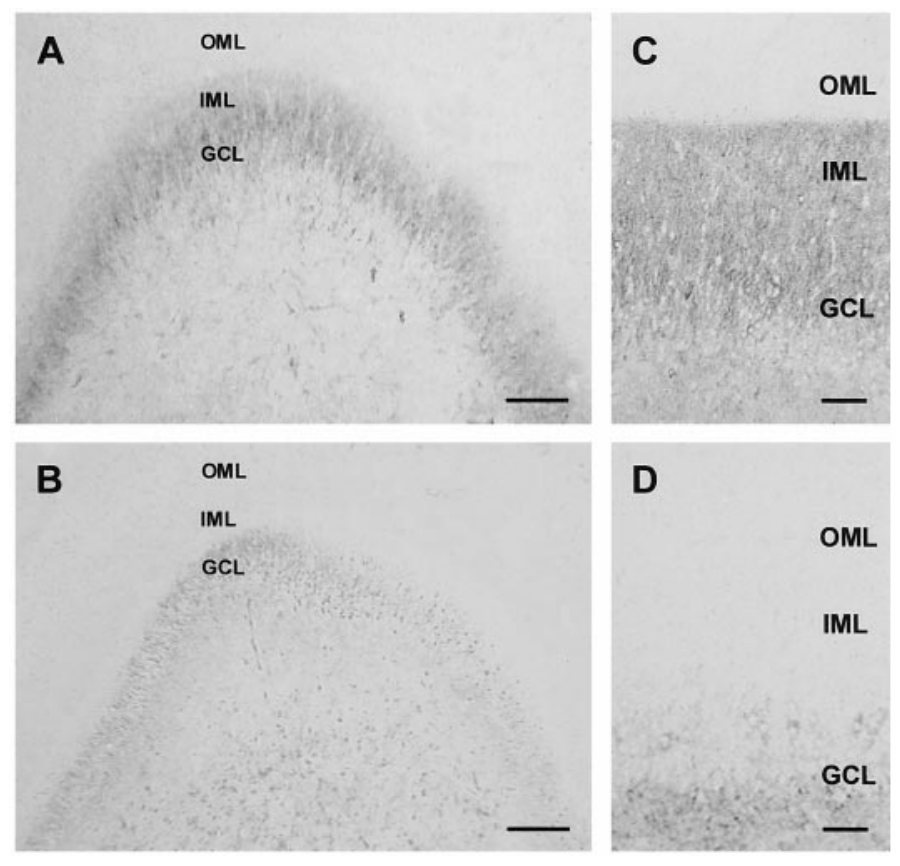

Figure 1. Dynorphin A immunoreactivity in the dentate gyrus (DG). $A$, TLE specimen with AHS. Dynorphin A immunoreactivity is found in the CA4 region, in the granule cell layer, and additionally in the inner molecular layer, indicating recurrent mossy fiber sprouting. $B$, Lesion-associated TLE specimen. Dynorphin A immunoreaction product is confined to the CA4 region and the granule cell layer. The dentate gyrus molecular layer is devoid of immunoreaction product. $C$, Higher magnification of the $\mathrm{DG}$ in $A$. $D$, Higher magnification of the DG in $B$. GCL, Granule cell layer; $I M L$, inner molecular layer; $O M L$, outer molecular layer. Scale bars: $A, B, 300$ $\mu \mathrm{m} ; C, D, 40 \mu \mathrm{m}$. In all specimens, dynorphin A immunoreactivity was found in granule cell bodies. In addition, clusters of immunoreaction product were observed in mossy fiber terminals within the CA4 and CA3 region. No specific immunoreaction product was present in the CA2 and CA1 region or in the subiculum. In the DG molecular layer, the specimens of the lesion-associated TLE group were devoid of immunoreaction product, whereas the AHS specimens revealed dynorphin A immunoreactivity throughout its inner portion, indicating recurrent mossy fiber sprouting.

CA1, CA3, and CA4 subfield and relative sparing of CA2 (Margerison and Corsellis, 1966; Blümcke et al., 1999) without any extrahippocampal pathology (AHS group, $n=18$ ). In these patients, pronounced mossy fiber sprouting could be invariably detected using dynorphin immunohistochemistry (Fig. $1 A, C$ ). In all of these patients, no additional extrahippocampal lesions could be found in imaging studies.

The second group of patients did not show either severe cell loss or mossy fiber sprouting in the hippocampus but had an epileptogenic lesion elsewhere in the temporal lobe (non-AHS group, $n=11$ ). The lack of mossy fiber sprouting in this group could be clearly shown by the lack of dynorphin immunoreactivity in the inner molecular layer of the dentate gyrus (DG) (Fig. 1B,D). The lesions comprised gangliogliomas, postischemic cystic lesions, one meningeoma grade I, one oligoastrocytoma grade III, one migration anomaly, and one caveroma (see Table 1). All of these lesions were found within the temporal lobe but did not involve the hippocampus proper. In two cases, the resected specimens showed no neuropathological abnormalities.

Spontaneous seizures recorded during presurgical evaluation with depth electrodes showed a hippocampal onset in the AHS group, whereas the non-AHS group invariably showed an extrahippocampal seizure onset. The rationale for resection of the hippocampus in the latter group was an early involvement of the hippocampus proper in seizure activity detected in depth electrode recordings.

We have determined whether the two groups are different with respect to further clinical criteria. The age of the patients at surgery, duration of the epilepsy, or seizure characteristics were not different between these two groups (Student's $t$ test). All patients were under a full anti-epileptic drug regimen at the time of operation (summarized in Table 1). The drug regimen included drugs such as carbamazepine (CBZ) or lamotrigine that acted on voltage-dependent sodium channels in most patients of both groups (CBZ-AHS: 14 of 18; lesion group: 8 of 12). The serum concentration of CBZ measured before the operation was not different between the groups (Student's $t$ test; see Table 1). Lamotrigine, which has a mechanism of action on voltage-dependent sodium and calcium channels similar to that of carbamazepine, was included in more patients of the AHS group (9 of 18) than in the lesion group (1 of 12). Because lamotrigine and CBZ have similar putative mechanisms of action, this differ- ence should not affect our results. Drugs putatively acting on the GABAergic system (clobazam, clonazepam, tiagabine, vigabatrin) were added in 4 of 18 and 4 of 12 patients in the AHS and lesion groups, respectively (NS, $\chi^{2}$ test).

In contrast to the previous patients (A1-18; L1-11) who suffered from epilepsy, one patient had an oligoastrocytoma grade III adjacent to the hippocampus proper (T1; see Table 1) and no history of epileptic seizures. In this patient, a small portion of hippocampus could be obtained from this specimen for electrophysiological analysis. For all further analyses, this patient was included in the lesion group. Informed consent was obtained from all patients for additional histopathological and electrophysiological evaluation. All procedures were approved by the ethics committee of the University of Bonn Medical Center and conform to standards set by the Declaration of Helsinki (1989).

Preparation and recording configuration. Human hippocampal specimens were obtained at resection and immediately placed in ice-cold ACSF containing (in mM): $\mathrm{NaCl} 124.0, \mathrm{KCl} 3.0, \mathrm{CaCl}_{2} 1.6, \mathrm{MgSO}_{4} 1.8, \mathrm{NaH}_{2} \mathrm{PO}_{4}$ 1.25, $\mathrm{NaHCO}_{3} 26.0$, D-glucose 10.0, pH 7.5, bubbled with $95 \% \mathrm{O}_{2} / 5 \% \mathrm{CO}_{2}$. After cooling for $3 \mathrm{~min}$, a transverse block from the body of the hippocampus was dissected with a razor blade and glued to the stage of a Vibratome (Leica VT 1000, Nussloch, Germany). Hippocampal slices $(400 \mu \mathrm{m})$ were prepared and transferred to a Haas-type interface chamber perfused with ACSF $(1.8 \mathrm{ml} / \mathrm{min})$ of a composition as above, with the addition of $100 \mu \mathrm{M}$ picrotoxin to block $\mathrm{GABA}_{\mathrm{A}}$-mediated responses. In some experiments, D-(-)-2-amino-5-phosphonovaleric acid (APV) was used to block NMDA receptors. The temperature of the recording chamber was slowly increased from room temperature to $30^{\circ} \mathrm{C}$ within $20 \mathrm{~min}$. At least $120 \mathrm{~min}$ were allowed for slice equilibration. Field EPSPs (fEPSPs) to perforant path stimulation were recorded with two borosilicate glass microelectrodes $(\sim 2$ $\mathrm{M} \Omega$ ) filled with extracellular solution in the dentate gyrus molecular layer and the granule cell layer. Stimulation was performed within the outer molecular layer, with two bipolar electrodes placed on opposite sides of the two recording electrodes to stimulate separate input pathways. Stimulation was performed with two $0.1 \mathrm{msec}$ current pulses with an interval of $50 \mathrm{msec}$ delivered via a stimulus isolator (WPI, Sarasota, FL) to monitor changes in paired-pulse properties. Both input pathways were alternately stimulated at $0.025 \mathrm{~Hz}$. The baseline stimulation strength was adjusted to elicit $50 \%$ of the maximal fEPSP amplitude. LTP in the perforant path was elicited with eight stimulus trains of 20 impulses at $100 \mathrm{~Hz}$ (intertrain interval $10 \mathrm{sec}$ ). The stimulation intensity was adjusted to the double baseline value. Signals were amplified with a field potential amplifier (Charité Berlin, Germany), filtered at $3 \mathrm{kHz}$, and digitized with a sampling frequency of $10 \mathrm{kHz}$ (ITC-16, Instrutech, Mineola, NY). Data were then transferred to hard disk for off-line analysis with the TIDA for Windows 2.61/2.64 acquisition and analysis package (HEKA Elektronik, LambrechtPfalz, Germany). Data were monitored on-line with an oscilloscope (Hameg, Frankfurt, Germany) and a chart recorder (Astro-Med, West Warwick, $\mathrm{RI})$. The maximal fEPSP slope was determined as a measure of the efficacy of synaptic transmission. If not stated otherwise, statistical differences were proven with a Mann-Whitney Wilcoxon Rank test.

A number of authors have held that epileptic seizures can induce a general and indiscriminate potentiation in hippocampal synapses that then occludes further LTP. To exclude the possibility that this could account for differences between our patient groups, we have selected patients that were under a full anti-epileptic drug regimen before surgery. Details of the drug regimen are given in Table 1. Patients were seizure-free at least $48 \mathrm{hr}$ before surgery, which was determined on the basis of behavioral observation of the patients before surgery. Slices showing spontaneous epileptiform activity that could conceivably have led to potentiation were excluded from analysis. Likewise, slices showing stimulus-induced epileptiform discharges or more than three repetitive population spikes were excluded.

Immunohistochemistry. Surgical specimens were obtained within $30 \mathrm{~min}$ after resection, immersion-fixed in $4 \%$ buffered formalin at room temperature for 8-48 hr, and embedded in paraffin. Immunohistochemistry was performed on $4 \mu \mathrm{m}$ paraffin sections. All hippocampal specimens were stained under identical conditions and processed in a single batch. After deparaffination, slides were incubated in $2 \%$ hydrogen peroxide (Merck, Darmstadt, Germany) diluted in methanol for 30 min, rehydrated, rinsed in PBS, transferred into $0.01 \mathrm{M}$ citrate buffer (Sigma, St. Louis, MO), boiled twice for $5 \mathrm{~min}$ in a microwave oven according to the standard Dako microwave treatment protocol, and rinsed in PBS. Preincubation with $2 \%$ goat serum (Vector Laboratories, Burlingame, CA), $10 \%$ fetal calf serum (Seromed, Berlin, Germany), and 5\% non-fat dry milk (Bio-Rad Laboratories, Hercules, CA) in PBS as a blocking reagent was performed for $2 \mathrm{hr}$ at $37^{\circ} \mathrm{C}$, followed by incubation with the polyclonal anti-dynorphin A-antibody $\left(1: 100\right.$, AHP373; Serotec) overnight at $4^{\circ} \mathrm{C}$. Binding of the primary antibody was detected by the avidin-biotin complex-peroxidase method (ABC Elite, Vector Labs) using 3,3'-diaminobenzidine (ICN, Cleveland, $\mathrm{OH}$ ) as a chromogen. Sections were dehydrated and mounted. Control experiments included omission of primary antibodies as well as substitution of the primary antibody by equivalent dilutions of nonimmune rabbit IgG serum (Dako, Glostrup, Denmark), using the same staining protocol, and were devoid of immunoreaction product. 

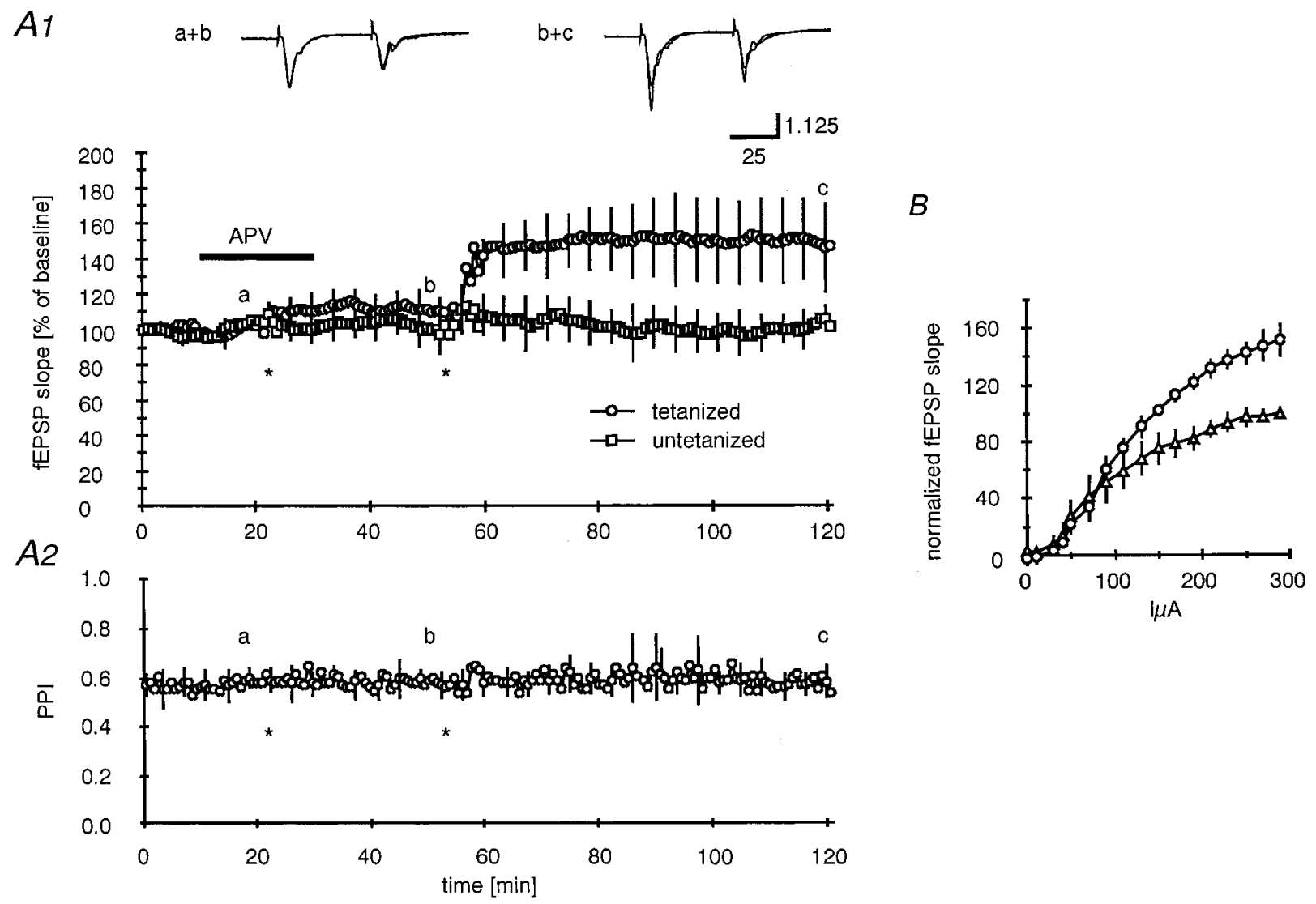

Figure 2. NMDAR-dependent LTP in human hippocampus. A1, Application of theta-burst stimulation (asterisk) induces potentiation of fEPSP slope in a stimulated $(\bigcirc)$ but not a nonstimulated reference input $(\square)$. Perfusion of $25 \mu \mathrm{M}$ APV (horizontal bar) blocks induction of LTP. Representative traces collected at the time points indicated by the lowercase letters are shown in the inset. A2, Paired-pulse index (PPI) calculated by the amplitude of the second of two fEPSPs divided by the first fEPSP amplitude $(50 \mathrm{msec}$ interstimulus interval) for the stimulated input. $B$, Input-output relations were constructed under baseline conditions $(\triangle)$ and $1 \mathrm{hr}$ after theta-burst stimulation $(\bigcirc)$. Values were normalized to the peak prestimulation amplitudes.

\section{RESULTS}

\section{NMDA receptor-dependent LTP in human hippocampus}

In 32 slices from 30 human subjects, we have recorded fEPSPs in the dentate gyrus molecular layer to stimulation of the perforant path. First, we have investigated human hippocampi that did not show severe damage (cell loss in the CA1 sector $<25 \%$, no recurrent mossy fiber sprouting, $n=6$ ). Unlike data from the rodent hippocampus, no discrimination of lateral or medial perforant path was possible on the basis of paired-pulse facilitation or depression, respectively. Rather, paired-pulse depression was seen in all recording positions when paired stimulation was performed with an interstimulus interval of $50 \mathrm{msec}(\mathrm{P} 2 / \mathrm{P} 1$ amplitude ratio $0.57 \pm$ 0.044 ) (Fig. 2A1,A2). Paired-pulse properties were not statistically different for stimulation intensities ranging from 50 to $300 \mu \mathrm{A}(50$ $\mu \mathrm{A}, \mathrm{P} 2 / \mathrm{P} 1$ amplitude ratio: $0.60 \pm 0.056)$. In all subsequent experiments, both the stimulating electrodes and the recording electrode were placed in the outer molecular layer near the hippocampal fissure.

In this group of patients, significant LTP of the fEPSP slope could be elicited readily in the perforant path by theta-burst stimulation $(147.9 \pm 25.3 \%$ after 1 hr) (Fig. $A 2 c)(n=6, p<0.05$ compared with prestimulation values). This applied to epilepsy patients with an epileptogenic lesion outside the hippocampus $(146.0 \%, n=5)$ as well as to a nonepileptic control hippocampus obtained during resection of a tumor (T1; Table 1) $(148.0 \%$ of baseline after $1 \mathrm{hr}$ ). Induction of LTP clearly required activation of NMDA receptors because perfusion of $25 \mu \mathrm{M}$ APV before application of theta-burst stimulation blocked the induction of LTP (Fig. $2 A 1)(n=4)$. Input-output relations recorded during baseline and $1 \mathrm{hr}$ after theta-burst stimulation are shown in Figure $2 B$. NMDAR-dependent LTP was elicited in an input-specific manner, because a second channel to which no theta-burst stimulation was applied (Fig. $2 A 1, \square$ ) showed no significant change $(103.2 \pm 10.2$ of baseline, NS). Paired-pulse depression was not changed after LTP induction (Fig. 2A2, NS). These experiments clearly show that the perforant path-dentate granule cell synapse in the adult human hippocampus can exhibit classical NMDAR-dependent LTP.

\section{Loss of LTP in patients with hippocampal damage}

Next, we investigated LTP in the hippocampus of patients showing a characteristic pattern of neuropathological damage restricted to the hippocampus proper that has been termed AHS. In this group, all hippocampi exhibited marked neuron loss in the CA1, CA3, and CA4 regions, with relative sparing of the dentate gyrus and the CA2 subfields. These hippocampi also showed marked recurrent mossy fiber sprouting detected by dynorphin immunohistochemistry (Fig. $1 A, C$ ). Similar to hippocampi from the lesion group, only paired-pulse depression could be found, regardless of the position of the stimulation electrode $(0.57 \pm 0.068)$. In marked contrast to morphologically intact hippocampi, an identical theta-burst stimulation produced low levels of LTP $(109.4 \pm 7.8, n=10$ after $1 \mathrm{hr})$ (Fig. 3A1,C) that was nevertheless NMDA receptor dependent $(n=5)$. Input-output relations recorded during baseline and $1 \mathrm{hr}$ after theta-burst stimulation are shown in Figure $2 B$. Similar to the lesion group, paired-pulse properties remained unchanged throughout this experiment (Fig. $3 A 2, \mathrm{NS}$ ).

\section{Depotentiation in patients with and without hippocampal damage}

Next, we investigated to what degree LTP can be depotentiated by application of a stimulus train at low frequencies $(1 \mathrm{~Hz}, 800$ impulses) in both patient groups $1 \mathrm{hr}$ after establishing LTP. In the lesion group, low-frequency stimulation significantly reduced 
$\overline{\text { Table 1. Summary of the patient data for } 18 \text { patients with Ammon's horn sclerosis (A1-A18) and 11 patients with lesion-associated epilepsy (L1-L11) }}$

\begin{tabular}{|c|c|c|c|c|c|c|c|c|c|}
\hline Code & $\begin{array}{l}\text { Age } \\
\text { at OP }\end{array}$ & Onset & Duration & Pathology & Seizure type & OP & Side & AEDs & $\begin{array}{l}\text { AED } \\
\text { levels }\end{array}$ \\
\hline A1 & 25 & 11 & 14 & AHS & CPS, SGS & sAHx & $\mathrm{R}$ & PHT & $14.2^{a}$ \\
\hline $\mathrm{A} 2$ & 41 & 4 & 37 & AHS & CPS, SGS & sAHx & $\mathrm{L}$ & CBZ, TGB & n.d. \\
\hline A3 & 45 & 17 & 28 & AHS & CPS, SGS & sAHx & $\mathrm{R}$ & CBZ, LTG & 7.3 \\
\hline A4 & 34 & 16 & 18 & AHS & CPS, SGS & sAHx & $\mathrm{L}$ & CBZ, LTG & 11.2 \\
\hline A5 & 4 & 2 & 2 & AHS & CPS & sAHx & $\mathrm{R}$ & CBZ, LTG & n.d. \\
\hline A6 & 17 & 4 & 13 & AHS & CPS & sAHx & $\mathrm{R}$ & PHT & n.d. \\
\hline A7 & 8 & 5 & 3 & AHS & CPS & sAHx & $\mathrm{L}$ & GVG & n.d. \\
\hline A 8 & 43 & 19 & 24 & AHS & CPS, SGS & sAHx & $\mathrm{R}$ & CBZ, VPR & 8.1 \\
\hline A9 & 55 & 33 & 22 & AHS & CPS, SGS & sAHx & $\mathrm{L}$ & CBZ, LTG, CLB & 10.6 \\
\hline A10 & 22 & 10 & 12 & AHS & SPS, CPS, SGS & sAHx & $\mathrm{R}$ & LTG, CLB & n.d. \\
\hline A11 & 16 & 12 & 4 & AHS & SPS, CPS & sAHx & $\mathrm{R}$ & CBZ, LTG & n.d. \\
\hline A12 & 34 & 22 & 12 & AHS & SPS, CPS, SGS & sAHx & $\mathrm{L}$ & $\mathrm{CBZ}$ & 7.4 \\
\hline A13 & 30 & 4 & 26 & AHS & SPS, CPS, SGS & sAHx & $\mathrm{R}$ & CBZ, LTG & 5.9 \\
\hline A14 & 34 & 20 & 14 & AHS & SPS, CPS, SGS & sAHx & $\mathrm{L}$ & CBC, LTG & 7.9 \\
\hline A15 & 12 & 10 & 2 & AHS & CPS & sAHx & $\mathrm{L}$ & $\mathrm{CBZ}$ & 4.8 \\
\hline A16 & 55 & 35 & 20 & AHS & SPS, CPS, SGS & sAHx & $\mathrm{L}$ & CBZ, VPA & 8.9 \\
\hline A17 & 40 & 29 & 11 & AHS & CPS & sAHx & $\mathrm{R}$ & CBZ, GBP & n.d. \\
\hline A18 & 24 & 1 & 23 & AHS & SPS, CPS & sAHx & $\mathrm{R}$ & CBZ, LTG & 6.2 \\
\hline L1 & 36 & 21 & 15 & Meningeoma (grade I) & SPS, CPS, SGS & Lesx + sAHx & $\mathrm{L}$ & $\mathrm{CBZ}, \mathrm{GBP}$ & 7.7 \\
\hline L2 & 44 & 15 & 29 & Ganglioglioma (WHO I) & SPS, CPS, SGS & Lesx + sAHx & $\mathrm{L}$ & PHT, GBP, CLB & n.d. \\
\hline L3 & 46 & 32 & 14 & Cavernoma & SPS, CPS, SGS & 2/3 TLx, sAHx & $\mathrm{L}$ & $\mathrm{CBZ}$ & 8.2 \\
\hline L4 & 19 & 10 & 9 & Ganglioglioma (WHO I) & SPS, CPS & Lesx + sAHx & $\mathrm{R}$ & $\mathrm{CBZ}$ & n.d. \\
\hline L5 & 5 & 2 & 3 & Cystic lesion & CPS & Hemispherectomy & $\mathrm{R}$ & GVG & n.d. \\
\hline L6 & 36 & 13 & 23 & Cystic lesion & CPS, SGS & $2 / 3 \mathrm{TLx}+\mathrm{sAHx}$ & $\mathrm{R}$ & VPR, LTG & n.d. \\
\hline L7 & 43 & 18 & 25 & Malformation & SPS, CPS, SGS & $2 / 3 \mathrm{TLx}+\mathrm{sAHx}$ & $\mathrm{R}$ & CBZ, CLB & 8.8 \\
\hline L8 & 18 & 12 & 6 & Cavernoma & SPS, CPS, SGS & Lesx + sAHx & $\mathrm{L}$ & $\mathrm{CBZ}$ & 9.8 \\
\hline L9 & 26 & 11 & 15 & & SPS, CPS, SGS & Lesx + sAHx & $\mathrm{R}$ & $\mathrm{CBZ}$ & 7.1 \\
\hline L10 & 50 & 49 & 1 & Anaplastic oligoastrocytoma (WHO III) & SPS & Lesx + sAHx & $\mathrm{R}$ & $\mathrm{CBZ}$ & \\
\hline L11 & 36 & 20 & 16 & & SPS, CPS & Lesx + sAHx & $\mathrm{R}$ & $\mathrm{CBZ}, \mathrm{CZM}$ & \\
\hline $\mathrm{T} 1$ & & & & Anaplastic oligoastrocytoma (WHO III) & None & Lesx & $\mathrm{L}$ & None & n.d. \\
\hline
\end{tabular}

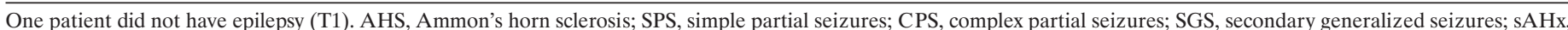

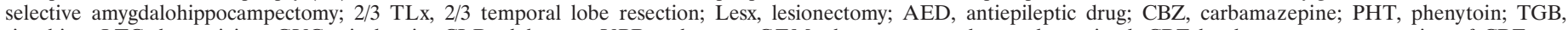

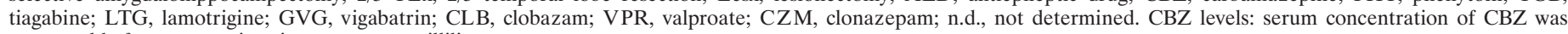
measured before surgery in micrograms per milliliter.

${ }^{a}$ Serum concentration of PHT is given.

fEPSP slope with respect to the post-LTP values $(p<0.05)$. However, the reversal of LTP proved to be only partial, with a significant difference compared with pre-LTP baseline levels $(120.4 \pm 4.3 \%$ relative to the initial baseline, $p<0.05)$ (Fig. 4, $\square$ ). The low amount of depotentiation may be caused by a limited time window within which reversal of LTP can occur by low-frequency stimulation (Staubli and Chun, 1996). In marked contrast, in the AHS group, application of prolonged $1 \mathrm{~Hz}$ stimulation after the potentiation protocol did not result in any change in fEPSPs (108.1 $\pm 10.7 \%$ of the initial baseline, NS) (Fig. 4, $\mathbf{\square})$.

\section{Loss of forskolin-induced LLP in patients with hippocampal damage}

A prominent feature of different hippocampal synapses is that pharmacological elevation of intraneuronal cAMP causes a longlasting potentiation that persists even after cAMP levels have returned to normal levels. This form of potentiation is thought to result from an enzymatic cascade that involves activation of protein kinase $\mathrm{A}$ and subsequent activation of different transcription factors. We have therefore asked whether long-lasting potentiation induced by coapplication of the adenylyl cyclase agonist forskolin $(50 \mu \mathrm{M})$ and the phosphodiesterase inhibitor isobutylmethylxanthine (IBMX) $(50 \mu \mathrm{M})$ is also impaired in hippocampi showing AHS. Application of forskolin/IBMX results in a significant gradual increase in fEPSP slope in hippocampi without AHS (172.1 \pm $16.9 \%, n=6 ; p<0.05$ ) (Fig. 5A1). In patients with AHS, no significant increases in fEPSP slope can be observed (108.5 \pm $21.5 \%$ of baseline after $2 \mathrm{hr}, n=9$; NS) (Fig. $5 A 1$ ). To test whether forskolin/IBMX-induced long-lasting potentiation occludes LTP, we have applied theta-burst stimulation after saturation of longlasting potentiation. Application of theta-burst stimulation did not result in further potentiation of perforant path fEPSPs. When the change in the fEPSP slope $1 \mathrm{hr}$ after theta-burst stimulation was expressed as a percentage of fEPSP measured immediately before theta-burst stimulation, the fEPSP slope was unchanged in the AHS group $(97.4 \pm 7.0 \%, n=3)$ and even resulted in a slight decrease of fEPSP slope in the non-AHS group $(87.4 \pm 8.0 \%, n=$ 8) (Fig. 5A1). This may be attributable to the fact that we did not decrease stimulus intensity until the fEPSP approximated the preforskolin fEPSP before we applied the theta-burst stimulation. Nevertheless, the data suggest that LTP and pharmacologically induced long-lasting potentiation rely on shared mechanisms, similar to rodents. Forskolin/IBMX-induced long-lasting potentiation did not result in any changes in paired-pulse properties (Fig. 5A2), as shown above for LTP induced by theta-burst stimulation.

\section{DISCUSSION}

Hippocampal synaptic plasticity has long been discussed as a possible, albeit controversial, correlate of memory processes in rodents. However, it is yet unknown whether activity-dependent modification of synaptic strength is also a fundamental property of 


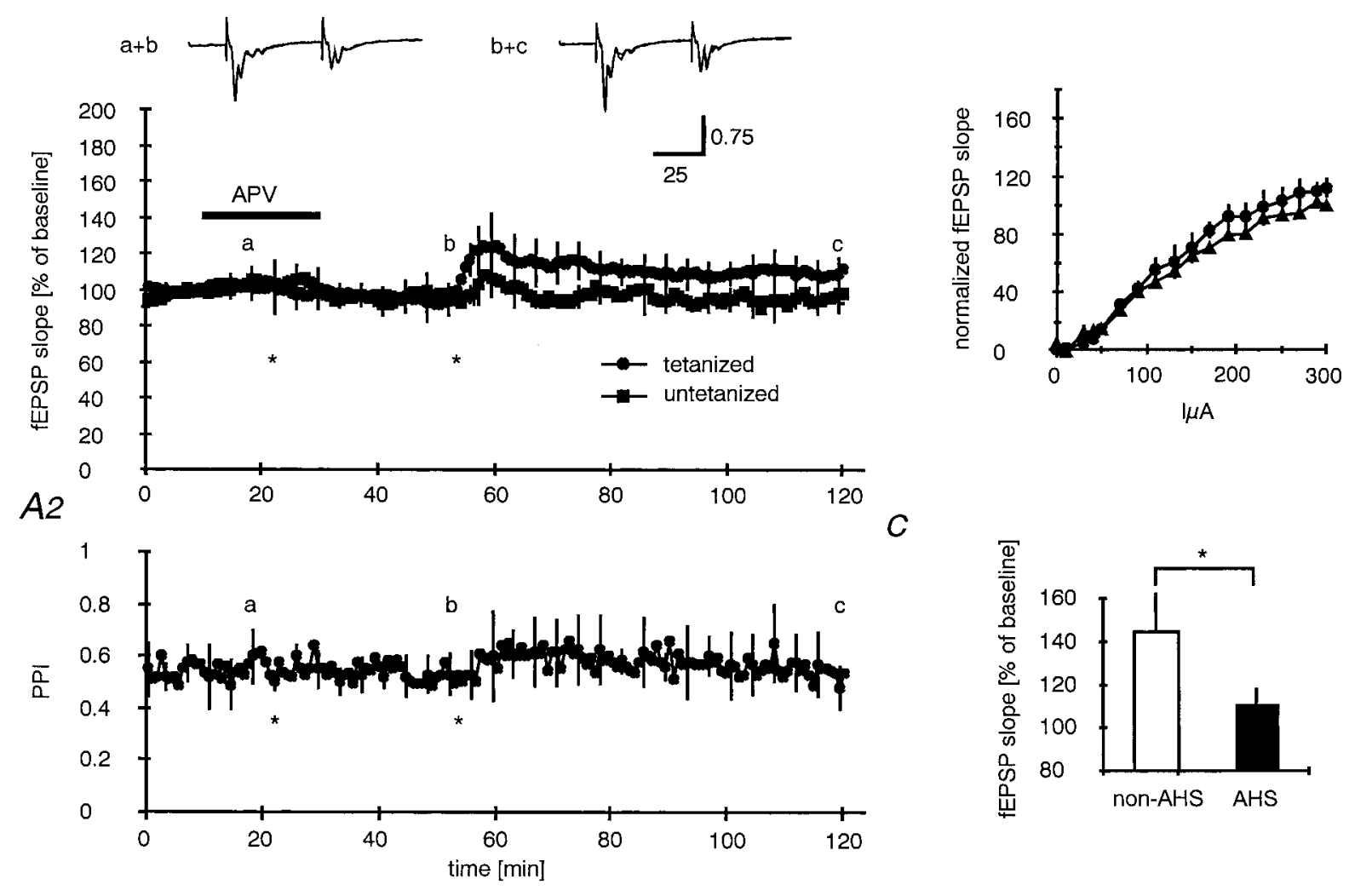

Figure 3. Loss of NMDAR-dependent LTP in epilepsy patients with a primary hippocampal seizure focus (AHS group). A1, Application of theta-burst stimulation (asterisk) induces only modest potentiation of fEPSP slope in the stimulated channel (@) (nonstimulated input, $\square$ ). Perfusion of $25 \mu \mathrm{M}$ APV (horizontal bar) blocks induction of LTP. Representative traces collected at the time points indicated by the lowercase letters are shown in the inset. A2, Paired-pulse index $(P P I)$ calculated by the amplitude of the second of two fEPSPs divided by the first fEPSP amplitude (50 msec interstimulus interval) for the stimulated input. $B$, Input-output relations were constructed under baseline conditions $(\boldsymbol{\Delta})$ and $1 \mathrm{hr}$ after theta-burst stimulation $(\boldsymbol{\bullet})$. Values were normalized to the peak prestimulation amplitudes. $C$, Summary of the amount of potentiation observed $1 \mathrm{hr}$ after the application of theta-burst stimulation relative to the prestimulation baseline.

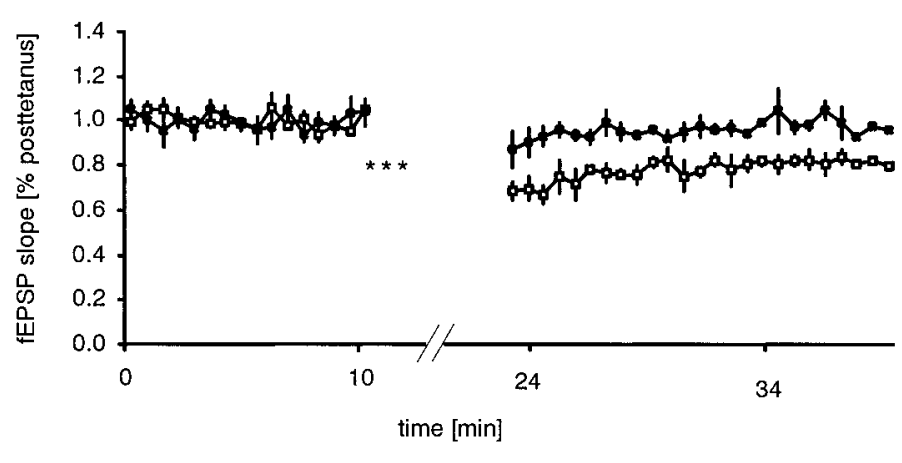

Figure 4. Depotentiation by low-frequency stimulation $(1 \mathrm{~Hz}, 800 \mathrm{im}$ -

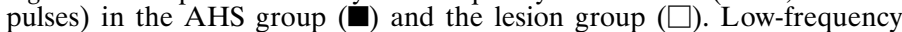
stimulation was applied 1 hr after induction of LTP by theta-burst stimulation. Depotentiation was measured $15 \mathrm{~min}$ after conclusion of lowfrequency stimulation.

human hippocampal synapses. Here we have taken advantage of the opportunity to obtain human hippocampal slices suitable for in vitro electrophysiology after neurosurgery. We show for the first time that synaptic potentiation can be readily induced in a human hippocampal synapse both by high-frequency stimulation and by pharmacologically increasing the intracellular cAMP concentration. LTP could be similarly elicited in a nonepileptic control hippocampus as well as in hippocampi from epilepsy patients that were not the primary seizure focus and did not show significant neuropathological damage. Thus, we have shown that a putative basic mechanism for memory processes in the rodent hippocampus is also present in the adult human hippocampus.
Several features of the perforant path-dentate granule cell synapse in the human suggest similarities to the medial perforant path in the rat. First, in our hands, increasing the intracellular cAMP concentration invariably caused LLP in human slices. This compares well with potentiation observed after application of $\beta$-adrenergic agonists in the rat medial perforant path, whereas depression occurs in the lateral perforant path (Stanton and Sarvey, 1985; Dahl and Sarvey, 1989). Second, fEPSPs in the human slices show paired-pulse depression, regardless of the position of the stimulation electrodes, a feature characteristic of the medial perforant path in the rat (Colino and Malenka, 1993). Third, paired-pulse properties of fEPSPs are unaltered after LTP induction in the human and the rat medial perforant path alike, whereas changes have been described in the rat lateral perforant path (Christie and Abraham, 1994). Finally, LTP in the human is blocked by NMDAR antagonists, similar to the rat medial perforant path (Errington et al., 1987; Burgard et al., 1989; Bramham et al., 1991), whereas the effects of NMDA antagonists in the rat lateral perforant path have been controversial (Bramham et al., 1991; Colino and Malenka, 1993; Bramham and Sarvey, 1996). This indicates that in the human slices investigated in this study, the distinction between medial and lateral perforant path is electrophysiologically less clear than in rodents. Otherwise, the properties of LTP in human hippocampal specimens seem to compare quite well with those described in the rodent medial perforant path (Hanse and Gustafsson, 1992; Colino and Malenka, 1993).

Next, we examined what effect the presence of a primary epileptic focus has on the ability to induce LTP. Temporal lobe epilepsy patients can be readily classified into two groups based on the localization of the primary epileptic focus by clinical, electrophys- 

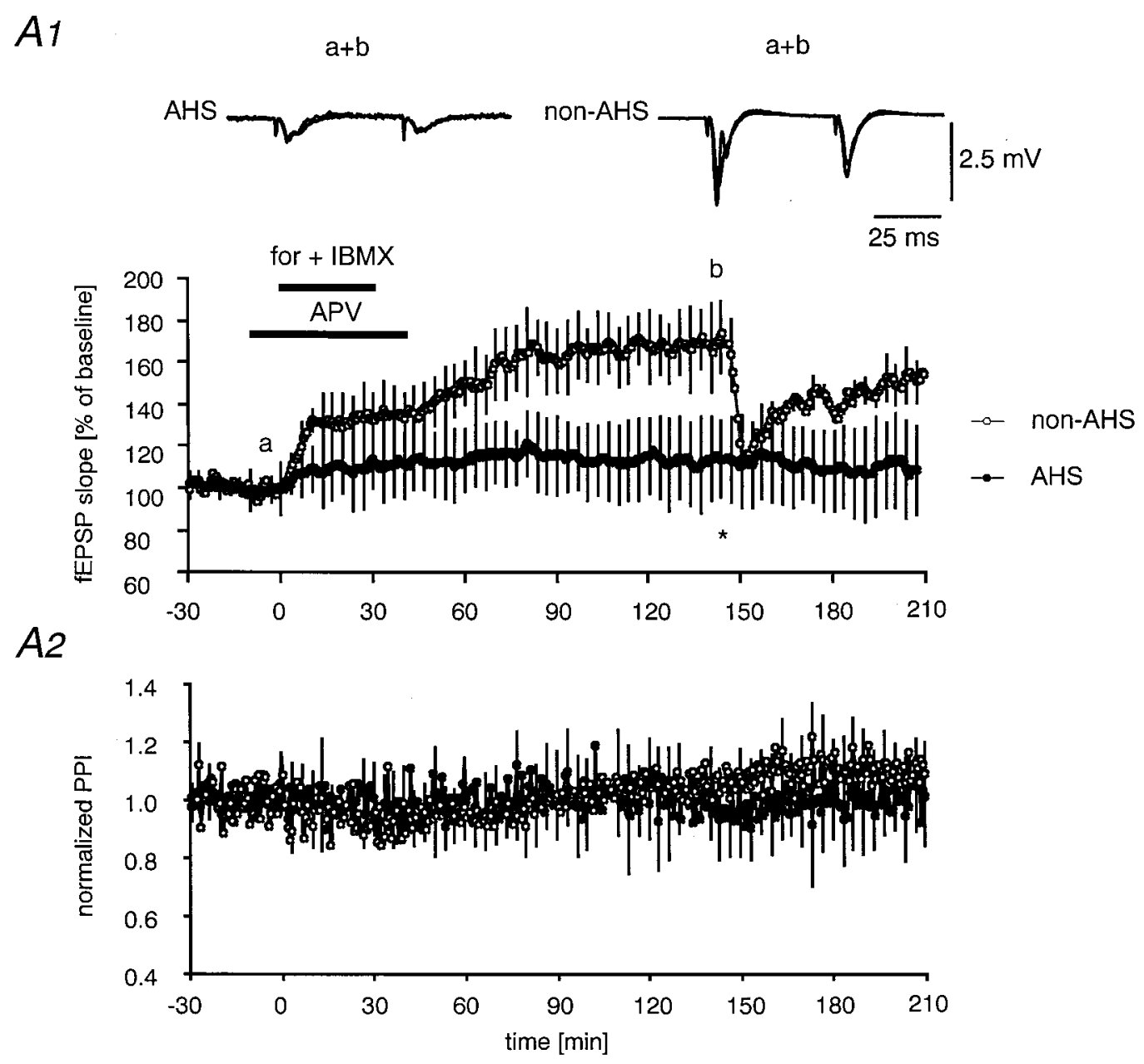

Figure 5. Long-lasting potentiation induced by forskolin/IBMX in human hippocampus. A1, A brief (30 min, horizontal bar) combined application of forskolin $(50 \mu \mathrm{M})$ and IBMX $(50 \mu \mathrm{M})$ in the presence of $25 \mu \mathrm{M}$ APV (horizontal bar) results in a long-lasting potentiation of the fEPSP slope in the non-AHS $(\bigcirc)$ but not the AHS group $(\bullet)$. A2, This treatment did not alter paired-pulse properties in either group. Representative traces collected at the time points indicated by the lowercase letters are shown in the inset of $A 1$.

iological, and neuropathological criteria. In one group, focal neuropathological damage within the Ammon's horn (AHS) is accompanied by a devastating loss in declarative memory performance (Helmstaedter et al., 1997) compared with patients without AHS or normal control subjects. In addition, measurement of intrahippocampal event-related potentials to word presentation has clearly shown a loss of discrimination between novel and previously presented words in patients with a hippocampal primary seizure focus (Grunwald et al., 1998). The second group shows an extrahippocampal primary seizure focus without severe hippocampal damage and only small neuropsychological abnormalities. We find that the presence of a primary epileptic focus is associated with a dramatically reduced capacity for synaptic potentiation. This applies to stimulation-induced LTP as well as to potentiation induced by pharmacologically raising cAMP levels. Likewise, prolonged low-frequency stimulation is ineffective in inducing depotentiation. Thus, it seems that in patients with a hippocampal primary seizure focus, a drastically reduced amount of synaptic modification is available for information processing. Indeed, the fact that neither LTP nor depotentiation could be elicited in these slices suggests that bidirectional modification of synaptic strength is severely impaired and that, instead, the synapse is "stuck" at a particular level of efficacy. Thus, a fundamental feature of most central synapses is lost in hippocampi shown to correspond to the primary epileptic seizure focus. The reasons for these changes are unclear, although some candidate mechanisms exist. For instance, some key enzymes involved in LTP and long-term depression are altered in human temporal lobe epilepsy (Lie et al., 1998). In addition, cell loss has been described in the entorhinal cortex of human patients with temporal lobe epilepsy (Du et al., 1995). Because the perforant path originates in this structure, selective neuron loss within the entorhinal cortex may have severe consequences for synaptic transmission in this pathway. However, given the multiple molecular and structural changes observed in human TLE, the reasons for loss of LTP in the AHS group of patients remain unclear.

Correlations of impaired synaptic plasticity and deficient performance in memory tasks have been observed in various animal models of human disease as well as in numerous transgenic animals. For instance, transgenic animal models for Alzheimer's disease show impaired LTP as well as defective spatial memory performance (Nalbantoglu et al., 1997; Chapman et al., 1999). Similar results have been obtained in transgenic mice lacking genes important in the induction or expression of LTP (Mayford et al., 1996). For instance, mutant mice lacking NMDARs in CA1 neurons or expressing activated CaMKII lose the capability to form place cells (McHugh et al., 1996; Rotenberg et al., 1996) and show deficient LTP and spatial learning (Rotenberg et al., 1996; Tsien et al., 1996). A particularly interesting recent study has found that age-related defects in spatial memory are correlated with defective late-phase LTP, which has been shown to be cAMP dependent. Furthermore, this group has demonstrated that agents that enhance the cAMP signaling pathway can reverse memory defects (Bach et al., 1999). Similar to these findings, both stimulationinduced LTP and LLP induced by raising the intracellular cAMP concentration are lost in the group of patients that shows defective declarative memory. Clearly, such parallel findings do not provide 
incontrovertible proof of a causal relationship of synaptic plasticity and memory processes. Indeed, in some investigations, genetic or pharmacological manipulations resulting in loss of LTP do not give rise to impaired memory function in specific tests (Bannerman et al., 1995; Saucier and Cain, 1995). Nevertheless, parallel investigations of LTP and memory performance have remained a major tool for probing the relation of synaptic plasticity and memory.

Here, we have shown that a loss of LTP and LLP occurs in a patient group with a primary hippocampal seizure focus. In previous neuropsychological studies, declarative memory performance has been shown to be reduced in such patients (Helmstaedter et al., 1997; Grunwald et al., 1999). Taken together, this suggests that loss of synaptic plasticity may be a candidate mechanism that contributes to loss in declarative memory. The reversibility of memory defects in animals by agents that enhance cAMP signaling and presumably also late LTP (Bach et al., 1999) suggests that such agents might be explored for use in human TLE patients with defective LTP and memory performance.

In summary, our results suggest that hippocampal synaptic plasticity is available as a possible basic mechanism for human declarative memory and that impaired synaptic plasticity may contribute to deficient declarative memory in human TLE.

\section{REFERENCES}

Bach ME, Barad M, Son H, Zhuo M, Lu YF, Shih R, Mansuy I, Hawkins RD, Kandel ER (1999) Age-related defects in spatial memory are correlated with defects in the late phase of hippocampal long-term potentiation in vitro and are attenuated by drugs that enhance the cAMP signaling pathway. Proc Natl Acad Sci USA 96:5280-5285.

Bannerman DM, Good MA, Butcher SP, Ramsay M, Morris RGM (1995) Distinct components of spatial learning revealed by prior training and NMDA receptor blockade. Nature 378:182-185.

Bliss TVP, Collingridge GL (1993) A synaptic model of memory: longterm potentiation in the hippocampus. Nature 361:31-39.

Bliss TVP, Lomo T (1973) Long-lasting potentiation of synaptic transmission in the dentate area of the anaesthetized rabbit following stimulation of the perforant path. J Physiol (Lond) 232:331-356.

Blümcke I, Beck H, Lie AA, Wiestler OD (1999) Molecular neuropathology of human mesial temporal lobe epilepsy. Epilepsy Res 36:205-223.

Bramham CR, Sarvey JM (1996) Endogenous activation of mu and delta-1 opioid receptors is required for long-term potentiation induction in the lateral perforant path: dependence on GABAergic inhibition. J Neurosci 16:8123-8131.

Bramham CR, Milgram NW, Srebro B (1991) Activation of AP5-sensitive NMDA receptors is not required to induce LTP of synaptic transmission in the lateral perforant path. Eur J Neurosci 3:1300-1308.

Burgard EC, Decker G, Sarvey JM (1989) NMDA receptor antagonists block norepinephrine-induced long-lasting potentiation and long-term potentiation in rat dentate gyrus. Brain Res 482:351-355.

Chapman PF, White GL, Jones MW, Cooper-Blacketer D, Marshall VJ Irizarry M, Younkin L, Good MA, Bliss TV, Hyman BT, Younkin SG Hsiao KK (1999) Impaired synaptic plasticity and learning in aged amyloid precursor protein transgenic mice. Nat Neurosci 2:271-276.

Christie BR, Abraham WC (1994) Differential regulation of paired-pulse plasticity following LTP in the dentate gyrus. NeuroReport 5:385-388.

Colino A, Malenka RC (1993) Mechanisms underlying induction of longterm potentiation in rat medial and lateral perforant paths in vitro. J Neurophysiol 69:1150-1159.

Dahl D, Sarvey JM (1989) Norepinephrine induces pathway-specific longlasting potentiation and depression in the hippocampal dentate gyrus. Proc Natl Acad Sci USA 86:4776-4780.

Davis S, Butcher SP, Morris RG (1992) The NMDA receptor antagonist D-2-amino-5-phosphonopentanoate (D-AP5) impairs spatial learning and LTP in vivo at intracerebral concentrations comparable with those that block LTP in vitro. J Neurosci 12:21-34.
Du F, Eid T, Lothman EW, Kohler C, Schwarcz R (1995) Preferential neuronal loss in layer III of the medial entorhinal cortex in rat models of temporal lobe epilepsy. J Neurosci 15:6301-6313.

Errington ML, Lynch MA, Bliss TVP (1987) Long-term potentiation in the dentate gyrus: induction and increased glutamate release are blocked by D-(-)-aminophosphonovalerate. Neuroscience 20:279-284.

Grant SGN, O’Dell TJ, Karl KA, Stein PL, Soriano P, Kandel ER (1992) Impaired long-term potentiation, spatial learning, and hippocampal development in fyn mutant mice. Science 258:1903-1910.

Grunwald T, Lehnertz K, Heinze HJ, Helmstaedter C, Elger CE (1998) Verbal novelty detection within the human hippocampus proper. Proc Natl Acad Sci USA 95:3193-3197.

Grunwald T, Beck H, Lehnertz K, Blumcke I, Pezer N, Kurthen M, Fernandez G, Van Roost D, Heinze HJ, Kutas M, Elger CE (1999) Evidence relating human verbal memory to hippocampal $N$-methyl-Daspartate receptors. Proc Natl Acad Sci USA 96:12085-12089.

Hanse E, Gustafsson B (1992) Postsynaptic, but not presynaptic, activity controls the early time course of long-term potentiation in the dentate gyrus. J Neurosci 12:3226-3240.

Helmstaedter C, Grunwald T, Lehnertz K, Gleissner U, Elger CE (1997) Differential involvement of left temporolateral and temporomesial structures in verbal declarative learning and memory: evidence from temporal lobe epilepsy. Brain Cogn 35:110-131.

Lie AA, Blumcke I, Beck H, Schramm J, Wiestler OD, Elger CE (1998) Altered patterns of $\mathrm{Ca}^{2+} /$ calmodulin-dependent protein kinase II and calcineurin immunoreactivity in the hippocampus of patients with temporal lobe epilepsy. J Neuropathol Exp Neurol 57:1078-1088.

Malenka RC, Nicoll RA (1993) NMDA-receptor-dependent synaptic plasticity: multiple forms and mechanisms. Trends Neurosci 16:521-527.

Margerison JH, Corsellis JAN (1966) A clinical, electroencephalographic and neuropathological study of the brain in epilepsy, with particular reference to the temporal lobes. Brain 89:499-530.

Mayford M, Bach ME, Huang YY, Wang L, Hawkins RD, Kandel ER (1996) Control of memory formation through regulated expression of a CaM KII transgene. Science 274:1678-1683.

McHugh TJ, Blum KI, Tsien JZ, Tonegawa S, Wilson MA (1996) Impaired hippocampal representation of space in CA1-specific NMDAR1 knockout mice. Cell 87:1339-1349.

Morris RGM (1989) Synaptic plasticity and learning: Selective impairment of learning in rats and blockade of long-term potentiation in vivo by the $N$-methyl-D-aspartate receptor antagonist AP5. J Neurosci 9:3040-3057.

Morris RGM, Anderson E, Lynch G, Baudry M (1986) Selective impairment of learning and blockade of long-term potentiation by an $N$-methylD-aspartate receptor antagonist, AP5. Nature 319:774-776.

Nalbantoglu J, Tirado-Santiago G, Lahsaïni A, Poirier J, Goncalves O, Verge G, Momoli F, Welner SA, Massicotte G, Julien JP, Shapiro ML (1997) Impaired learning and LTP in mice expressing the carboxy terminus of the Alzheimer amyloid precursor protein. Nature 387:500-505.

Rotenberg A, Mayford M, Hawkins RD, Kandel ER, Muller RU (1996) Mice expressing activated CaMKII lack low frequency LTP and do not form stable place cells in the CA1 region of the hippocampus. Cell 87:1351-1361.

Saucier D, Cain DP (1995) Spatial learning without NMDA receptordependent long-term potentiation. Nature 378:186-189.

Silva AJ, Paylor R, Wehner JM, Tonegawa S (1992a) Impaired spatial learning in $\alpha$-calcium-calmodulin kinase II mutant mice. Science 257:206-211.

Silva AJ, Stevens CF, Tonegawa S, Wang Y (1992b) Deficient hippocampal long-term potentiation in alpha-calcium-calmodulin kinase II mutant mice. Science 257:201-206.

Squire LR (1992) Memory and the hippocampus: a synthesis from findings with rats, monkeys, and humans. Psychol Rev 99:195-231.

Stanton PK, Sarvey JM (1985) Depletion of norepinephrine, but not serotonin, reduces long-term potentiation in the dentate gyrus of rat hippocampal slices. J Neurosci 5:2169-2176.

Staubli U, Chun D (1996) Factors regulating the reversibility of long-term potentiation. J Neurosci 16:853-860.

Tsien JZ, Huerta PT, Tonegawa S (1996) The essential role of hippocampal CA1 NMDA receptor-dependent synaptic plasticity in spatial memory. Cell 87:1327-1338. 